\title{
Variations
}

Variations Revue internationale de théorie critique

\section{Dix thèses sur le marxisme à l'heure actuelle (1950)}

\section{Karl Korsch}

Traducteur : Alexander Neumann

\section{(2) OpenEdition}

\section{Journals}

\section{Édition électronique}

URL : https://journals.openedition.org/variations/1943

DOI : 10.4000/variations. 1943

ISSN : 1968-3960

\section{Éditeur}

Les amis de Variations

\section{Référence électronique}

Karl Korsch, « Dix thèses sur le marxisme à l'heure actuelle (1950) », Variations [En ligne], 24 | 2021,

mis en ligne le 03 juillet 2021, consulté le 07 juillet 2021. URL : http://journals.openedition.org/

variations/1943; DOI : https://doi.org/10.4000/variations.1943

Ce document a été généré automatiquement le 7 juillet 2021.

Les ami•e•s de Variations 


\title{
Dix thèses sur le marxisme à l'heure actuelle (1950)
}

\author{
Karl Korsch
}

Traduction : Alexander Neumann

\section{NOTE DE L'ÉDITEUR}

Karl Korsch fut l'un des co-fondateur de l'Institut de Francfort (Institut für Sozialforschung) en 1923, alors en lice pour être son premier directeur, ministre de la justice du gouvernement des gauches en Thuringe la même année, dirigeant du parti communiste allemand, puis opposant de gauche au stalinisme. Le présent texte est la traduction d'un manuscrit pour une conférence que Korsch a donné à Zurich en 1950.

1 I. Il ne fait plus aucun sens de poser la question de savoir, dans quelle mesure les enseignements de Marx et Engels seraient aujourd'hui encore valables théoriquement, et applicables en pratique.

II. Toutes les tentatives de rétablir une doctrine marxiste dans son intégrité, dans sa fonction d'une théorie de la révolution sociale de la classe ouvrière, sont des utopies réactionnaires à l'heure actuelle.

III. Cependant, pour le meilleur et le pire, d'importants éléments des enseignements de Marx continuent d'agir, dans des rôles et des domaines qui ont changé. De même, la praxis de l'ancien mouvement ouvrier marxiste a impulsé les motivations actuelles de peuples et de classes dans leurs confrontations pratiques, d'une manière importante.

IV. Le premier pas sur la voie d'une reconstruction d'une théorie et d'une praxis révolutionnaire consiste à rompre avec la prétention monopoliste du marxisme envers les initiatives révolutionnaires et ses directions théoriques et pratiques.

V. Aujourd'hui, Marx fait figure d'une des nombreux précurseurs, fondateurs et continuateurs des mouvements socialistes de la classe des travailleurs. Aussi important sont les ainsi nommés 'socialistes utopiques', depuis Thomas Moore jusqu'au présent. 
6 Au premier rang desquels comptent les concurrents politiques de Marx tel Blanqui, et les adversaires comme Proudhon et Bakounine. D'une importance égale sont les discussions ultérieures, qui touchent au révisionnisme allemand, à l'anarchosyndicalisme français et au bolchévisme russe.

VI. Les points les plus problématiques du marxisme sont:

8 1. Sa dépendance pratique des conditions économiques et politiques en Allemagne, ainsi que dans l'ensemble des pays de l'Europe centrale et orientale où il a gagné un rôle politique plus tard.

9 2. Le maintien inconditionnel des formes politiques de la révolution bourgeoise

10 3. L'acceptation inconditionnelle de l'état économique avancé en Angleterre, en tant que modèle pour le développement futur de tous les autres pays et en tant que condition préalable pour le passage au socialisme. A cela s'ajoute -

4. Les effets et conséquences de ses efforts crispés, de battre en brèche ces conditions.

VII. Ces conditions sont la source de :

1. L'exagération du rôle de l'Etat en tant qu'instrument décisif de la révolution sociale

2. L'identification mythique du développement de l'économie capitaliste avec la révolution sociale par la classe ouvrière

15 3. La ramification ultérieure, ambigüe, de cette première forme de la théorie révolutionnaire marxienne à qui fut ajouté artificiellement une théorie dite des deux phases de la révolution communiste, dirigée pour partie contre Blanqui, pour partie contre Bakounine, une ramification théorique qui occulte l'émancipation des travailleurs au présent pour l'éloigner vers un avenir indéterminé.

VIII. C'est ici que le développement léninien ou bolchévique du marxisme débute, et qui est la forme à travers laquelle le marxisme fut transposé à la Russie et à l'Asie. A travers ce mouvement s'est alors concrétisé la transformation du socialisme marxiste, celle d'une théorie révolutionnaire vers une idéologie, qui fut alors mise au service de toute une série d'objectifs politiques et qui peut encore servir toute sorte d'objectif.

IX. De ce point de vue, les deux révolutions russes de 1917 et de 1928 doivent faire l'objet d'une analyse critique, et cette position critique doit fonder l'appréciation des fonctions que remplit aujourd'hui le marxisme en Asie et à l'échelle planétaire.

$18 \mathrm{X}$. La maitrise des travailleurs de la production de leurs propres vies ne pourra pas se réaliser en remplaçant les positions qu'ont abandonnées les propriétaires monopolistes sur les moyens de productions sur les marchés internationaux et le marché mondial, qui abolissent la prétendue concurrence libre. Pareille maitrise ne pourra provenir que d'une intervention concertée de toutes les classes, qui en sont aujourd'hui exclues, dans la production qui tend actuellement à être planifiée et régulée de manière monopolistique. 